\title{
Lezama Lima lee a Sor Juana
}

\author{
Olga BEATRIZ SANTIAGO \\ Universidad Nacional de Córdoba. Argentina \\ olgasantiago@sinectis.com.ar
}

\section{RESUMEN}

El Sueño de Sor Juana Inés de la Cruz ha provocado desde su escritura un abanico de interpretaciones. Los estudiosos han identificado en sus versos postulados propios del neoplatonismo, del hermetismo, del cartesianismo, de filosofía tomista. Sin embargo, para José Lezama Lima este poema todavía no ha sido leído en profundidad. En el ensayo "La curiosidad barroca", que integra el libro La expresión americana (1957), el escritor cubano propone una lectura distinta del poema en varios sentidos.

En principio, inscripta en el horizonte polémico que caracteriza la relación del arte europeo con el americano, la lectura lezamiana reconoce en el Sueño las huellas de la audaz gesta de contraconquista que secretamente expresan las formas del arte Barroco en estas tierras. Pero, además, sostiene que asistimos en los versos de Sor Juana al despliegue de un apetito desmesurado por el conocimiento. El poema encierra un saber alcanzado en la experiencia poética protagonizada por el alma durante el sueño y configurada en analogía con el modo de conocimiento órfico que impregna la concepción lezamiana del mundo. Este trabajo examina los factores que el escritor pondera en su lectura del Sueño en procura de recuperar el sentido secreto que descubre en los versos.

Palabras clave: José Lezama Lima, Sor Juana Inés de la Cruz, sueño, orfismo.

\section{Lezama Lima read Sor Juana}

\begin{abstract}
Sor Juana Inés de la Cruz's Sueño has led a varied range of interpretations. Scholars have identified, in her verses, tenets of neo-platonism, hermeticism, cartesianism and scholastic philosophy. However, in Lezama's opinion, this unbeatable poem and unparalleled in American literature, has not yet been read in depth. In the essay "The Baroque curiosity" from the book The American expression (1957), the Cuban writer proposes a different reading of the poem by Sor Juana in several ways.

In principle, registered in the controversial horizon that characterizes the relationship of European art with American, Lezama's interpretation recognized, in the Dream, the traces of the daring exploits of contra-conquest secretly express the Baroque art forms in these lands. But also he argues that assist in the verses of Sor Juana the deployment of an inordinate appetite for knowledge. The poem contains a knowledge achieved in the poetic experience starring the soul during sleep and configured in analogy mode Orphic knowledge that permeates the Lezamian worldview. This paper examines the factors that the writer ponders
\end{abstract}


in his reading of Dream in an attempt to recover the secret meaning he discovers in the verses.

Key words: José Lezama Lima, Sor Juana Inés de la Cruz, dream, orphism.

SUMARIO: 1.Barroco arte de contraconquista. 2.El apetito de conocimiento.

Piramidal, funesta, de la tierra nacida sombra, al cielo encaminaba de vanos obeliscos punta altiva escalar pretendiendo las estrellas.

(De la Cruz 1995: 335)

En el ensayo "La curiosidad barroca" que integra el libro La expresión americana (1957), José Lezama Lima abre la posibilidad de leer el Sueño de sor Juana Inés de la Cruz, que ha provocado desde su escritura un abanico variado de interpretaciones, desde una perspectiva distinta a la asumida por la crítica tradicional. A lo largo de los años, los estudiosos han advertido en los versos del famoso poema, las huellas del neoplatonismo, de hermetismo, de cartesianismo, de filosofía tomista ${ }^{1}$. Sin embargo, para Lezama este poema insuperable y sin par en la literatura americana todavía no ha sido leído en su profundidad:

Algún día cuando los estudios literarios superen su etapa de catálogo y se estudien los poemas como cuerpos vivientes, o como dimensiones alcanzadas, se precisará la cercanía de la ganancia del sueño en sor Juana. (Lezama Lima 1981: 393)

El maestro de La Habana nos propone una nueva lectura del poema de Sor Juana en varios sentidos. En principio, lee la obra de Sor Juana integrando la gesta de reivindicación criolla que se libra en el siglo XVII, perspectiva desde donde sostiene que, más que un arte de la Contrarreforma, el Barroco en América ostenta los rasgos de un arte de contraconquista.

\section{Barroco arte de contraconquista}

A diferencia de las crónicas hispanas del siglo XVI, las obras del Barroco colonial se inscriben en un horizonte polémico que guarda relación con la necesidad de los criollos en el siglo XVII de conseguir el reconocimiento de su dignidad, de

\footnotetext{
${ }^{1}$ En relación a estos estudios pueden citarse, entre otros, los trabajos de Elías Trabulse que hace énfasis en la tendencia al hermetismo en los versos, de Octavio Paz que los inscribe en la corriente neoplatónica, o bien, de Soriano Vallés y Beuchot que identifican rasgos de cartesianismo y filosofía tomista en el poema de Sor Juana.
} 
refutar la subestimación española. Atentos al conflicto entre peninsulares y criollos, es posible leer en las expresiones artísticas las huellas del complejo de inferioridad de los americanos.

Las postulaciones del cubano en este sentido en La Expresión americana permiten integrar los ensayos de su libro a la red discursiva que conforma el alegato en defensa de la dignidad de los criollos iniciada en el siglo XVII. En su lectura rechaza la desvalorización crítica del arte americano colonial en tanto emulaciones degradadas de modelos metropolitanos, niega que su carácter epigonal sea problemático y constituya necesariamente una incapacidad para la novedad ${ }^{2}$. Tampoco acepta que la posibilidad de originalidad americana se sustente en la incorporación de componentes autóctonos en formas de raíz europea; lo que se requiere, para el autor de Paradiso, es la audacia de reconocerse en pie de igualdad con los europeos:

Nuestro punto de vista parte de la imposibilidad de dos estilos semejantes, de la negación del desdén a los epígonos [...] He ahí el germen del complejo terrible del americano: creer que su expresión no es forma alcanzada, sino problematismo, cosa a resolver. Sudoroso e inhibido por tan presuntuosos complejos, busca en la autoctonía el lujo que se le negaba, y acorralado entre esa pequeñez y el espejismo de las realizaciones europeas, revisa sus datos, pero ha olvidado lo esencial, que el plasma de su autoctonía es tierra igual que la de Europa. (1981: 376)

La inscripción del arte barroco en esta pugna artístico-discursiva europeo / americano, explica el planteo relacional del cubano al comenzar su ensayo "La curiosidad barroca" entre el arte europeo, al que le asigna carencias constitutivas, "acumulación sin tensión y asimetría sin plutonismo" (1981: 384), y el arte nativo que, en ventajosa comparación, cualifica por la presencia de tensión y plutonismo o fuego transmutador, con lo cual se refiere a la capacidad incorporativa, permanentemente asimilativa y nutricia de nuestro Barroco que le permite alcanzar formas novedosas y un sentido plenario.

${ }^{2}$ La mirada no eurocéntrica sobre las letras del Barroco colonial, iniciada tempranamente por Pedro Henríquez Ureña en Seis ensayos en busca de nuestra expresión (1928) y seguida por Lezama Lima, se condensa luego progresivamente desde los años 1980-1990, a partir de los estudios sobre el sujeto criollo de Bernard Lavallé, los análisis de la práctica de los letrados coloniales tanto de Ángel Rama como de Magdalena Chocano Mena, y el enfoque americanista en los trabajos de Mabel Moraña, Rolena Adorno, María Alba Pastor Llaneza, Jacques Lafaye, Raquel Chang-Rodríguez, José Antonio Mazzotti, Beatriz GonzálezStephan, John Beverley entre otros. Por este camino, algunos de ellos asumen una revisión de las letras del Barroco americano y, sin desconocer su carácter dependiente, también advierten una adaptación creativa en América. 
En el corpus seleccionado para caracterizar la estética en el ensayo, Lezama busca identificar los rasgos que manifiestan la capacidad de los artistas para desprenderse del referente modélico y, en un contexto colonial, lograr dar expresión a la novedad americana estratégicamente disimulada en las formas propias del código estético.

En su interpretación, las formas barrocas guardan la huella de una gesta, la hazaña por conquistar la expresión propia y, en consecuencia, por alcanzar el reconocimiento del nativo en la convivencia cultural. Entonces, frente a la tesis de Werner Weisbach en su libro El Barroco, arte de la Contrarreforma (1942), Lezama entiende que estas expresiones mejor se definen como un arte de contraconquista. Su argumentación hace énfasis en que el Barroco constituye la primera expresión genuina americana y que su aparición coincide con el momento del despertar de una conciencia nativa, de un sujeto de identidad diferente "que construye el sueño de propia pertenencia" (1981: 385).

En este marco de condiciones puede leer en las obras la existencia de un acto de atrevimiento de un sujeto heroico. La gesta de un artista que adquiere forma, entre otros, en los trabajos de arquitectura y escultura del indio Kondori y el Aleijadinho o en los versos de Sor Juana. Con la riqueza mineral de la propia naturaleza realiza el indio Kondori la gran hazaña del Barroco americano, al lograr insertar en la piedra cuzqueña de la iglesia de la Compañía: "los símbolos incaicos de sol y luna, de abstractas elaboraciones de sirenas incaicas, de grandes ángeles cuyos rostros de indios reflejan la desolación de la explotación minera" (1981: 397). La gesta triunfal del indio Kondori inaugura un nuevo tiempo en la relación cultural "fue el primero que, en los dominios de la forma, se ganó la igualdad con el tratamiento de un estilo por los europeos. [...], consecuentemente, su heroísmo redunda en un bien colectivo: Ahora, gracias al heroísmo y conveniencia de sus símbolos, precisamos que podemos acercarnos a las manifestaciones de cualquier estilo sin acomplejarnos" (1981: 398).

Pero si el indio Kondori "representa la rebelión incaica", un reclamo de aceptación y reconocimiento, un pacto de convivencia y respeto por la cultura incaica, el Aleijadihno, dueño de un espíritu libre y decididamente creador, se opone a los modos estilísticos de su época e impone los suyos y de este modo, a fines del siglo XVIII, se alza con la gloria de la conquista de la expresión artística americana que anuncia el proceso revolucionario independentista en América

el triunfo prodigioso del Aleijadihno, que prepara ya la rebelión del próximo siglo; es la prueba de que se está maduro ya para una ruptura. He ahí la prueba más decisiva, cuando un esforzado de la forma, recibe un estilo de una gran tradición, y lejos de amenguarlo, lo devuelve acrecido, es un símbolo de que ese país ha alcanzado su forma en el arte de la ciudad. Es la gesta que en el siglo siguiente al Aleijadihno, va a realizar José Martí (1981: 398). 
En el conjunto artístico que pondera integrando la reivindicación criolla, Lezama destaca la obra de ingenio de la monja mexicana que logra despertar la admiración de los letrados locales y peninsulares de su época.

Sor Juana Inés de la Cruz alcanza su plenitud y la plenitud del idioma poético en sus días. Es la primera vez que una figura americana ocupa un lugar de primacía. En el reinado de Carlos II, donde ya asoma la recíproca influencia americana sobre lo hispano, es la figura central de la poesía. (1981: 392)

Asigna a Sor Juana no solo el privilegio de inaugurar la expresión poética en las nuevas tierras sino también de iniciar un movimiento de reciprocidad de influencias que pone en pie de igualdad los dos mundos, carácter que incluye su obra en la sigilosa gesta de contraconquista que se libra en estilo Barroco durante el período colonial.

\section{El apetito de conocimiento}

Conforme a la inventio lezamiana desplegada en "La curiosidad barroca", a la mesa del figurado banquete barroco, en la que se sientan a la par letrados europeos y americanos, donde cada uno aporta lo suyo para saciar el apetito artístico, sor Juana con su poema contribuye con el "aceite" que alimenta los "faroles sacros" y que proviene del fruto del olivo, aludido en figura mitológica del "árbol del Minerva" (diosa de sabiduría), es decir, contribuye con la sustancia nutricia de un saber de origen divino conseguido con mucho esfuerzo.

De esta manera, Lezama alude al tema central en el Sueño, donde Sor Juana da forma a su pasión intelectual, "es una lucha invisiblemente heroica, soterrada pero situada en el centro mismo de su vida" (1981: 392); el poema es, entonces, expresión de su inquietud más profunda y secreta: su insaciable e irrenunciable curiosidad.

Los diversos saberes de la ciencia universal (teología, filosofía, ciencias, música, matemática, astronomía) encuentran, dice Lezama, su cauce natural en las obras del Barroco de estas tierras que se manifiesta siempre tan "amistoso de la Ilustración" (1981: 386). En el Sueño de la monja mexicana, advierte la presencia de conceptos de la quinta parte del Discurso del método para conducir bien la propia razón y buscar la verdad en las ciencias (1637) de René Descartes, libro prohibido en su circulación en América al que, es altamente probable, la autora accediera por su amistad con don Carlos de Sigüenza y Góngora. También señala la incidencia en los versos de nociones provenientes de Ars Magna. Lucis et umbrae (Arte del magnetismo. Luz y sombra) (1671) del jesuita alemán Atanasio Kircher, notable intelectual del siglo XVII conocido como el último sabio humanista que quiso saberlo todo. En este gusto por trabajar en poesía con saberes de origen científico como es el caso de las obras de Sigüenza y Góngora y de Sor Juana-, reconoce 
Lezama una particularidad que diferencia e identifica al estilo en América y que subrayará en el título del ensayo: "La curiosidad barroca".

En relación al epígrafe que encabeza el poema y declara la filiación gongorina de los versos - "imitando a Góngora"-, el cubano entiende que "es una humildad encantadora más que una verdad literaria" - (1981: 392), ya que identifica en el poema una dimensión significativamente distinta al planteo de las Soledades de Góngora $^{3}$. Hay para él un abismo entre los planteos temáticos y aspiraciones de ambos poetas; mientras la poesía del cordobés está impregnada de sensualismo y tiende en ascensión gótica hacia la $\mathrm{luz}^{4}$, el alma, protagonista de la aventura de conocimiento en el Sueño, se abandona a la incitación neptúnica y desciende a las profundidades llevada por el sueño.

La experiencia descripta en los versos "Es lo más opuesto a un poema de los sentidos" (Lezama Lima 1981: 392). El cuerpo duerme mientras las facultades del alma están activas; retirada del mundo exterior el alma emprende un viaje secreto por las moradas subterráneas del sueño. La interpretación acuerda con la concepción mítica y órfica del mundo del propio Lezama: "Las alusiones a Proserpina, Ascálafo, el sombrío chismoso, están dirigidas y encajadas en muy otra dirección que la gongorina" (Lezama Lima 1981: 392).

En articulación con el mito órfico los versos acumulan referencias a la cultura egipcia, al poeta Homero, a Plutón, el Hades, al mito fuente de Aretusa y, en relación con el orfismo, resuenan en el poema la doctrina de la doble naturaleza humana, por un lado, de origen divino y, por otro, terrenal, en permanente tensión, la noción del cuerpo como cárcel del alma y su necesidad de liberación, el sumergimiento del alma en un ámbito nocturno-infernal, la comprensión del hombre como "bisagra engazadora" (De la Cruz 1995: 351) entre lo celestial y terrenal (Herrero de Jáuregui). Pero no sólo estas referencias habilitan la lectura lezamiana del Sueño en registro órfico. En los primeros versos del poema asistimos a la ascensión de la sombra:

Piramidal, funesta, de la tierra

nacida sombra, al cielo encaminaba

${ }^{3}$ En relación al epígrafe que aparece en ediciones antiguas, a partir de la de 1692: "Primero Sueño que así intituló y compuso, la Madre Juana Inés de la cruz, imitando a Góngora", Antonio Alatorre entiende que, quien nos está dando la noticia, no sostiene que el lenguaje del poema es imitación del de Góngora sino que se tituló así por seguir la "Primera Soledad" del cordobés, incluso que por esto no se apocopa "Primer" (Alatorre 1997: 103-104). Por su parte, Robert Ricard considera que el título antiguo en que se hace alusión a Góngora es iniciativa de los editores no de la autora, que lo llama simplemente el Sueño en Carta a Sor Filotea de la Cruz (1975: 26).

${ }^{4}$ En "sierpe de don Luis de Góngora" Lezama afirma que "El ha creado en la poesía lo que pudiéramos llamar el tiempo de los objetos o los seres en la luz" (Lezama Lima 1981: 241). 
de vanos obeliscos punta altiva

escalar pretendiendo las estrellas

(De la Cruz 1995: 335)

Es la sombra la que ambiciona alcanzar las estrellas dibujando una pirámide de oscuridad que resulta el doble en figura del recorrido del alma en el sueño que va del inframundo al ámbito celestial. En el mismo registro, en Paradiso el escritor distingue dos noches: "Una era la noche estelar que descendía con el rocío. La otra era la noche subterránea, que ascendía como un árbol, que sostenía el misterio de la entrada a la ciudad" (Lezama Lima 1981: 450). Las sombras en ascenso configuran el inicio de un proceso hacia la luz, de un movimiento transformador, metamorfoseante de lo real. Para alcanzar la luz es preciso como Orfeo recorrer las sombras, el espacio del inframundo.

Un concepto central en el Orfismo es la noción de la noche en su carácter generador, reproductor, su poder creativo, fecundante. En "Introducción a vasos órficos", dice Lezama, "el orfismo ha escogido la Noche, majestuosa guardiana del huevo órfico" (1981: 335). En el mismo ensayo sostiene que en un "Himno a la noche" de los órficos "aparece ésta como la generatriz, fuente del universo" (1981: 336), "Todo nuevo saber, utilizando sentencias de los coros eleusinos, ha brotado siempre de la fértil oscuridad" (1981: 338), del mundo subterráneo. En el poema de sor Juana la bajada a las profundidades del sueño corresponde a la bajada a los infiernos de Orfeo, y si la figura mítica baja en busca de su amada Eurípides para traerla de nuevo a la vida, el alma en el poema baja al sueño en busca de lo desconocido para alzarlo a la luz.

En la noche órfica el movimiento ascendente del alma requiere antes el descenso al sueño. Otra noción axial en el orfismo es la idea de continuidad, al descenso sigue el ascenso, de la oscuridad se genera la luz, a la muerte sigue la vida, la resurrección, en un proceso continuo, en un inacabado ciclo de repeticiones. Podría decirse al revés, en el mundo órfico la luz surge de la oscuridad. El poema comienza describiendo la noche, reino de la oscuridad, del silencio y acaba en un movimiento inverso, con la llegada del día, "repartiendo los colores y entreabriendo los sentidos", dice Lezama Lima (1981: 393).

La caracterización del sueño en analogía con la muerte es innegable en los versos de sor Juana:

el cuerpo siendo, en sosegada calma, un cadáver con alma, muerto a la vida y a la muerte vivo, (De la Cruz 1995: 340) 
El cuerpo parece muerto pero está vivo. La imagen paradojal resuelve la contradicción órfica de una muerte que contiene vida, capacidad generadora, resurrección; al sueño sigue siempre el despertar.

En el descenso a las profundidades del sueño, correlato del descenso al inframundo, el alma busca develar un misterio, apoderarse de un conocimiento prohibido. El reino de las sombras, la oscuridad y el silencio es el ámbito de un secreto que se aspira conocer -dominio de Proserpina, Ascálafo, el sombrío chismoso-, se pretende saber, sacar de las sombras como a Eurídice, acción que encuentra expresión en la reiteración del lexema "asombro" en los versos. Al referir la posibilidad de sacar remedio del veneno, luz de la sombra, dice en el poema:

¡que así del mal el bien tal vez se saca!-:

no de otra suerte el Alma, que asombrada

de la vista quedó de objeto tanto,

(De la Cruz 1995: 348)

El ámbito de las sombras resulta, entonces, propicio para ir en búsqueda del conocimiento, favorece el desprendimiento de lo no conocido que aparece como regalo de la oscuridad. Mientras la capacidad seductora de la luz distrae, la pasividad de sentidos exteriores en el dormir favorece la concentración en el acto y la posibilidad de conseguir desprendimientos. La noche y el sueño permiten entonces el ascenso de la sombras hacia la luz, del no saber al saber, del ámbito terrenal de la materia (cuerpo), al celestial y divino.

Por otra parte, hay en los versos un movimiento de profundización gradual, un ritmo lento expresado por gerundios, "escalar pretendiendo las estrellas" (De la Cruz 1995: 335), que también distancian el poema de los ágiles versos gongorinos. No hay prisa en el Sueño, el enunciador se detiene en la descripción del funcionamiento de los órganos vitales del cuerpo humano e imprime a los versos el aspecto durativo que expresa el proceso del sueño: "Parece como si remedase la lenta corriente de un río sumergido, mientras la sustancia del sueño va horadando y penetrando aquellos pasajes" (Lezama Lima 1981: 392).

Para el cubano los versos de sor Juana "Parecen surgidos en el centro de concurrencia de sus ejercicios poéticos con sus lecturas escolásticas" (Lezama Lima 1981: 392), es decir en la confluencia de Poesía y Filosofía. Conforme lo ha señalado Soriano Vallés, reconoce que en el poema las nociones sobre fisiología de los órganos del cuerpo humano son claramente de origen escolástico "en Sor Juana es la escolástica del cuerpo la que pasa íntegra a su poema" (Lezama Lima 1981: 392) y, en su criterio, la monja mejicana supera en su audacia a Lope de Vega en los poemas de La Circe. Entre las alusiones a la anatomía escolástica en los versos, Lezama destaca la referencia al "Húmedo radical" que define a la sustancia fundamento del mundo: 
parece como si aludiese a nuestros propios bosques animados con la profundidad maternal de la noche... Su oscuridad desciende a nuestras profundidades, para fundirse con lo inexpresado, impidiendo que la luz al invitarlo ahuyente, y favorecer su desprendimiento por el descenso a las profundidades que siempre regala la oscuridad. (1981: 393)

La bajada del alma al sueño en los versos alcanza entonces, el sentido de una auténtica inmersión en lo profundo, en el genuino magma americano -que delatan los pronombres posesivos "nuestros"- en busca de lo propio aún inexpresado.

Sin embargo, el enunciador en Lezama modaliza sus afirmaciones y las inscribe en el orden del "parecer", a su criterio esto alcanza explicación por el modo superficial de tratar el mito de Sor Juana, ya que no difiere de la manera renacentista o del modo en que luego aparecerá en los Sonetos a Orfeo de Rainer María Rilke o de Paul Valéry en poemas a Narciso, "simple presentación o presencia, ahondada por referencias personales disimuladas [...] que así viene a darle sombra de profundidad" (Lezama Lima 1981: 393).

La monja mexicana es poeta, pero no es una iniciada en la doctrina de los misterios órficos sino una aficionada al saber, lo que explica para Lezama que sus visiones no alcancen una "forma viviente". El alma temeraria, protagonista de la aventura de conocimiento, se orienta por intuición (como Platón, luego Descartes), aspira al modo órfico de conocer por revelación, en un intuitivo acto todo lo creado. Impulsada por una pasión desmedida avanza hasta que, en un momento, el temor la detiene y retrocede cobarde. Dice en los veros previos a la caída del alma:

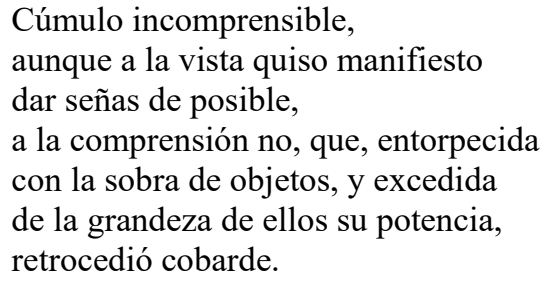

En palabras de Lezama el alma se mueve por "una sana pasión de aficionado, una curiosidad complaciente con el terror y que después con aniñado gesto mide la desproporción y se esconde quejumbroso" (Lezama Lima 1981: 394). Desproporción del objeto de conocimiento pero también desproporción en el deseo del sujeto de conocimiento que provocan la detención del proceso, el arrepentimiento -"se esconde quejumbroso"-. El acto de conocimiento se asume en el poema como gesto de audacia, como atrevimiento, osadía, transgresión y hasta pecado, al que queda asociada en el texto bíblico la actitud de esconderse (Adán, Caín). La falta es la desmesura, la desproporción entre lo que el sujeto ambiciona saber y las posibilidades humanas. Lezama reconoce en el desmesurado afán de 
conocimiento que expresan los versos la ambición humana de dominar el mundo, el afán fáustico por el conocimiento que desde sus orígenes ha inquietado al hombre, la curiosidad edénica e inevitable:
Así, en el sueño, Sor Juana utiliza el símbolo mitológico de la fuente de Aretusa, que trocada en río sumergido recorre tanto las moradas infernales de Plutón como los placenteros Campos Elíseos, continúa la lucha por aprehender el milagro del mundo diurno, el afán fáustico de que el conocimiento sea una realidad y que esa realidad pertenezca por entero al hombre (1981: 393).

Por su atrevimiento desmesurado, el alma en el Sueño cae en el pecado de soberbia, es culpable; y cabe consignar que la noción de culpa es de génesis órfica antes que cristiana. La ambición por saber, la curiosidad sin límites es peligrosa y representa una falta grave que implica castigo divino. Orfeo se vuelve a mirar lo prohibido y pierde a Eurídice para siempre y en el relato bíblico es la causa de la expulsión del hombre del paraíso.

Sin embargo, a pesar de la caída, a pesar de la culpa, Lezama no entiende un fracaso en la experiencia del alma; por el contrario, ella "extrae" un saber sobre "graduaciones del ser, para recibir el conocimiento" (1981: 393), es decir, sobre las potencialidades de cada especie de criatura en el orden del saber, en una cadena de jerarquías que va del animal, el hombre a los ángeles-inteligencias puras, en términos escolásticos.

La diferencia en el modo de tratar el tema del sueño en Sor Juana respecto a los románticos alemanes y a los surrealistas nos dice el cubano: "consiste en que no se trata de buscar otra realidad, otra mágica causalidad, sino con visible reminiscencia cartesiana, el sueño aparece como forma de dominio de la superconciencia" (1981: 393) Mediante la imagen - de reminiscencia cartesiana - se alude a los ojos del alma racional que alcanza un saber intuitivo-deductivo mientras el cuerpo duerme. El dormir permite al alma "el viaje secreto de nuestras comunicaciones con el mundo exterior por las moradas subterráneas" (1981: 393); la experiencia de conocimiento es descripta, entonces, como un viaje o itinerario que implica un proceso de encadenamientos entre fenómenos de naturaleza disímil.

Pero hay más, dice Lezama: "Hay una sabiduría, parece desprenderse del poema, en el sueño, pero trabajada sobre la materia de la inmediata realidad" (1981: 393). Interpreta, entonces, que los versos disimuladamente delatan una continuidad entre el mundo de la conciencia y el sueño en orden al conocimiento. Continuidad que se repite en los espacios referenciados a partir del mito: las moradas infernales de Plutón como los placenteros Campos Elíseos, continuidad entre el mundo diurno y el nocturno en que el afán de conocimiento no se interrumpe. Del mismo modo que el alma, protagonista de la aventura de conocimiento en el poema, necesita del alimento - la materia - porque cuando siente hambre se despierta, su posibilidad de conocer durante el sueño depende de la información del mundo exterior guardada 
en la memoria. La conciencia sigue trabajando en el sueño alimentada con los datos sensibles o informaciones adquiridas en la inmediata realidad, y, en efecto, es posible en el sueño adquirir un saber tan válido como el de la conciencia despierta.

Si tenemos en cuenta que la filosofía aristotélico-tomista consideraba los sueños como "imaginaciones" falsas por carecer de referencias concretas a la realidad (Soriano Vallès 2000: 98), Sor Juana en la lectura de Lezama toma distancia de esta noción y disimuladamente postula, doscientos años antes que el desarrollo de las teorías del psicoanálisis, la posibilidad de conocer en el sueño. Con disimulo se sostiene entonces en el poema, la continuidad del trabajo del alma racional entre el sueño y la vigilia, entre el mundo exterior y el de la imaginación, la fantasía, a la vez que se afirma la imposibilidad del alma de desprenderse del cuerpo.

Finalmente, el maestro de La Habana postula en su interpretación del poema una analogía entre el saber en el sueño y saber poético: las propiedades del sueño quedan asimiladas a su concepción poética. Hay en ambas experiencias un modo de conocimiento intuitivo y casi mágico, al modo de revelaciones órficas, donde el saber es un milagro que se entrega, a veces: "Ah, que tú escapes en el instante / en el que ya habías alcanzado tu definición mejor", dice en su poema "Enemigo rumor", en que refiere la dificultad del asimiento de lo poético (Lezama Lima 1975: 663). De esto se deriva el encuentro de similitud entre las facultades de encantamiento del sueño-Morfeo y del poeta cantor-Orfeo quien va al Hades en busca de Eurídice, emblema de la poesía. La poesía como el sueño es un ámbito de fecundidad, conduce a una penetración en lo creativo, en el ritmo universal del deseo que genera todas las posibilidades de creación. El alma en el Sueño de la monja mexicana pertenece a un poeta que alcanza "por conocimiento poético la misma vivencia del conocimiento mágico" (Lezama Lima 1981: 393), en consecuencia, la figura del poeta se afilia al mago, al adivino. Leemos en el ensayo cubano "El poeta está todo lleno de esa adivinación que revela un asombro y que se vuelve sobre él con procedimientos aún no cabales para llevarlos a una forma viviente." (1981: 393).

A pesar de las debilidades señaladas, Lezama admira a Sor Juana: "no hay antes ni después de ese poema, en lo que se refiere al sueño, al sujeto del poema, en nuestra literatura, una intención que lo iguale ni una forma adquirida que lo supere" (1981: 394); subraya la excepcionalidad de los versos que logran configurar un microcosmos poético, consiguen alcanzar esos raros momentos de concurrencia, de gravitación, de intuición poética y de conocimiento del alma. Es lícito releer ahora, desde otro lugar, su advertencia al iniciar la lectura del poema: "Algún día cuando los estudios literarios superen su etapa de catálogo y se estudien los poemas como cuerpos vivientes, o como dimensiones alcanzadas, se precisará la cercanía de la ganancia del sueño en sor Juana" (Lezama Lima 1981: 393).

Otro acto temerario de Sor Juana, semejante al del Sueño, apuntado en su lectura es la celebración de la deidad náhuatl del dios de la semilla en la loa al auto sacramental de "El Divino Narciso" en el que logra un punto de confluencia entre 
creencias europeas y americanas. Con estos gestos entiende el cubano que la monja contribuye a inaugurar un tiempo de paz después de la violenta conquista: "Como si esa caída grave en el sueño fuese transformando las divinidades de la sangre y la ira en los nuevos dioses del óleo y la reconciliación" (1981: 394). Espíritu de reconciliación órfico que, en el ensayo "A partir de la poesía" - La cantidad hechizada - identifica en la tercera era imaginaria, temporalidad definida por la paradigmática figura de Orfeo quien "conoce su destino y lo cumple, aún en la muerte" (Lezama Lima 1981: 322).

La lectura lezamiana permite, entonces, al poema de Sor Juana adquirir, en alguna medida, un cuerpo viviente y así, encarnar la rebeldía criolla, enarbolar las demandas de reconocimiento de dignidad nativa y gestionar con voz propia un tiempo de confluencia de la cultura europea y americana. A la vez, los versos son expresión de la lucha del hombre por trascender los límites de su conocimiento, la que es configurada como una experiencia de búsqueda temeraria que combina alma y cuerpo, vigilia y sueño, mundo exterior e imaginación, sombra y luz.

Entre los pliegues barrocos del poema, Lezama descifra una encubierta rebeldía al método escolástico de conocimiento como única vía de acceso al saber en la época y, en cambio, prefiere una integración de la imaginación poética, la curiosidad científica, fe religiosa y saber mítico; una combinación de posibles asedios a la verdad que se corresponde con la concepción cristiana de armonía universal. En especial, su lectura descifra, frente al supuesto fracaso del alma en su aventura de conocimiento, una ganancia: entre sus versos se disimula un secreto robado al sueño que resulta equivalente al modo de saber poético.

En el ensayo titulado: "Mitos y cansancio clásico" de La expresión americana, señala la necesidad de hacer renacer y renovar viejos mitos del mundo clásico mediante el ingenio criollo: "Todo tendrá que ser reconstruido, invencionado de nuevo, y los viejos mitos, al reaparecer de nuevo, nos ofrecerán sus conjuros y sus enigmas con un rostro desconocido" (Lezama Lima 1981: 373). En la lectura del Sueño de sor Juana, con inaudita audacia, el autor logra concretar esta profecía desplazada y al hacerlo, renace el poema con nuevo rostro provocador. Y es ahora Lezama quien, cual nuevo Orfeo, va al pasado a sacarlo de las sombras e incitar su resurrección.

\section{BIBLIOGRAFÍA}

ADORNO, Rolena.

1986 "Literary Production and Suppression: Reading and Writing about Amerindians in Colonial Spanish America", Dispositio, Revista Hispánica de Semiótica Literaria, vol. XI, nº 28-29, pp. 1-25. 
Alatorre, Antonio.

1997 "Lectura del Primero Sueño", en Sara Poot Herrera y Elena Urrutia (coords.), $Y$ diversa de mi misma entre vuestras plumas ando. Homenaje internacional a Sor Juana Inés de la Cruz. México: Colegio de México, pp. 101-127.

BEUCHOT, Mauricio.

2005 Sor Juana: una filosofia barroca. Alicante: Biblioteca Virtual Miguel de Cervantes.

http://www.cervantesvirtual.com/nd/ark:/59851/bmcnk3q1

BEVERLEY, John.

1981 "Sobre Góngora y el gongorismo colonial", Revista Iberoamericana no 114-115, pp. 33-44.

CHANG-RODRÍGUEZ, Raquel.

1991 El discurso disidente: Ensayos de literatura colonial peruana. Lima: Pontificia Universidad Católica del Perú.

Chocano Mena, Magdalena.

2000 La Fortaleza Docta. Elite letrada y dominación social en México colonial (siglos XVI-XVII). Barcelona: Bellaterra.

DE LA CRUZ, Sor Juana Inés.

1995 “El Sueño", en Alfonso Méndez Plancarte (ed.), Obras completas, tomo I. México: Fondo de Cultura Económica, pp. 335-361.

GONZÁlEZ STEPHAN, Beatriz.

1993 "Sujeto criollo/conciencia histórica: la historiografía literaria en el período colonial". En José Anadón (ed.) Ruptura de la conciencia hispanoamericana (Época colonial), Madrid: University of Notre Dame-Fondo de Cultura Económica, pp. 9-57.

HERRERO DE JÁUREGUI, Miguel.

2007 Tradición órfica y cristianismo antiguo. Madrid: Editorial Trotta. LAFAYE, Jacques.

1995 Quetzalcóatl y Guadalupe. México: Fondo de Cultura Económica. LAVALLÉ, Bernard.

1993 Las promesas ambiguas. Ensayos sobre el criollismo colonial en los Andes. Lima: Pontificia Universidad Católica del Perú. Instituto Riva-Agüero.

LEZAMA LIMA, José.

1981 La expresión americana, en El reino de la Imagen. Caracas: Biblioteca Ayacucho, pp. 369-441.

1981 "Introducción a vasos órficos", en El reino de la Imagen. Caracas: Biblioteca Ayacucho, pp. 334-341.

MAzzotTI, José Antonio.

2000 "Introducción”, en José Antonio Mazzotti (ed.), Agencias criollas. La ambigüedad "colonial" en las letras hispanoamericanas. 
Pittsburgh: Instituto Internacional de Literatura Iberoamericana, MORAÑA, Mabel.

Universidad de Pittsburgh, pp. 7-35.

1998 Viaje al Silencio. Exploraciones del discurso barroco. México:

Facultad de Filosofía y Letras, Universidad Autónoma de México.

PASTOR LlaneZA, María Alba.

1994 "Criollismo, religiosidad y barroco", en Bolívar Echeverría (comp.), Modernidad, mestizaje cultural, ethos barroco. México: Universidad Autónoma de México, pp. 171-298.

PAZ, Octavio.

1983 Sor Juana Inés de la Cruz o las trampas de la fe. México: Fondo de Cultura Económica.

RAMA, Ángel.

1984 La Ciudad Letrada. Hanover: Ediciones del Norte.

RICARD, Robert.

1975 "Reflexiones sobre El sueño de Sor Juana Inés de la Cruz", Revista de la Universidad de México, tomo XXX, nº 4, pp. 25-32.

SORIANO VALLÉS, Alejandro.

2000 El Primero Sueño de Sor Juana Inés de la Cruz. Bases tomistas. México: Universidad Nacional Autónoma de México, Instituto de Investigaciones Estéticas.

TRABULSE, Elías.

1984 "El hermetismo de Sor Juana Inés de la Cruz", en El círculo roto. México: Fondo de Cultura Económico-SEP. 